\title{
Predicting the Remaining Service Life of Civil Airport Runway considering Reliability and Damage Accumulation
}

\author{
Baoli Wei iD $^{1,2}$ and Chengchao Guo iD $^{3}$ \\ ${ }^{1}$ School of Civil Engineering and Architecture, Zhengzhou University of Aeronautics, Zhengzhou 450046, China \\ ${ }^{2}$ School of Water Conservancy and Environment, Zhengzhou University, Zhengzhou 450001, China \\ ${ }^{3}$ School of Civil Engineering, Sun Yat-Sen University, Zhuhai 519082, China \\ Correspondence should be addressed to Baoli Wei; bdgway@yeah.net
}

Received 25 November 2021; Revised 16 December 2021; Accepted 18 December 2021; Published 17 January 2022

Academic Editor: REN Fuqiang

Copyright (C) 2022 Baoli Wei and Chengchao Guo. This is an open access article distributed under the Creative Commons Attribution License, which permits unrestricted use, distribution, and reproduction in any medium, provided the original work is properly cited.

\begin{abstract}
Based on the MEPDG method, the operation process of MEPDG was analyzed and the MEPDG correction method applied to the remaining life prediction of airport pavement was obtained. According to the theory of structural reliability, the performance function of airport pavement was obtained based on the limit state equation represented by flexural stress. Considering the characteristics of airport cement concrete pavement design, the calculation formula of the number of allowable load actions was obtained based on reliability by NCHRP126 fatigue equation without considering the temperature stress when the flexural fatigue strength of pavement plate cement concrete was less than 1.25 times of the design strength. Based on the actual situation of local civil airport runways in Henan Province, the proposed MEPDG correction method was used to analyze the flexural stress of the actual operating airport runway pavement at $95 \%$ reliability level based on the mechanical numerical model of airport runway, and the number of allowable load actions of three aircraft models was obtained. Given the impact of pass-to-coverage ratio P/C, the cumulative damage factor CDF of the major aircraft models was calculated; the annual average growth rate of different aircraft models in the airport pavement evaluation stage was obtained based on the trend extension method. According to the predicted average annual cumulative damage, the remaining life of pavement was predicted. Compared with the actual conditions of the airport, the remaining life predicted in this paper was consistent with the actual life, which verifies the effect of the prediction of the remaining life of airport runway considering the impact of reliability and damage accumulation.
\end{abstract}

\section{Introduction}

In the mid-20th century, the airport management department for the airport runway only proposed "a palliative rather than a cure" for the operation and maintenance. In the early 10 years of the 21 st century, the airport management department cast away the passive postmaintenance and adopted the preventive maintenance, a more active maintenance, to reduce the frequency of damage. Preventive maintenance is a timebased maintenance, but it will cause runway maintenance in an uneven manner: the consistent maintenance cycle will lead to unnecessary maintenance in some pavements but improper maintenance in other pavements. Also, the preventive maintenance is up to the expertise of technicians and is the lack of data support.

Currently, predictive maintenance (PdM), which emerges in many sectors, especially industry, is a typical way of intelligent maintenance. As a data-driven maintenance mode, it is an integration of sensor technology, signal processing technology, reliability analysis, statistics, machine learning, and other methods for determining potential diseases, which lays a foundation for a more reasonable and effective maintenance plan [1] Remaining Service Life (RSL) can be used by civil engineers to schedule maintenance times, optimize operational efficiency, and avoid unplanned stops. Therefore, predicting RSL should be prioritized in the predictive maintenance. 
Therefore, in this paper, the remaining life prediction method of the airport runway was analyzed. The operation process of MEPDG was analyzed and summarized, and the MEPDG correction method was applied to the remaining life prediction of the airport runway. MEPDG provides technical support for the maintenance decision of airport runway and also provides reference for reasonable allocation of limited operation and maintenance funds in the airport management department [2].

\section{Current Research Studies on the Remaining Life Prediction of Airport Pavement}

The input in the RSL prediction model is the state indicator of airport runway. The features are taken from the monitoring sensor data or daily maintenance data, and behavior changes with runway performance degradation or usage state changes, but the changes can be predicted based on the model. RSL prediction methods applied to predictive maintenance can be divided into three categories: similarity prediction, performance degradation model prediction, and survival curve prediction methods.

At present, as a representative method, the similarity prediction method is the constrained polynomial regression model proposed by American scholar Shahin [3]. This model is very practical. It has been incorporated into the MicroPaver system [4] and has been widely used in countries around the world. In addition, the two-parameter nonlinear model created by Chinese scholar Sun Lijun is widely used in China [5]. At the same time, many researchers have studied the similarity prediction methods [6-9].

To study the performance degradation model based on the prediction method for the remaining life prediction of airport runway, most scholars at home and abroad fit a general fatigue equation using the site or laboratory data from performance degradation equation of a linear or exponential function. Then, they use the fatigue equation as the performance degradation model for predicting the future performance degradation process of airport runway, to further predict the remaining life of airport runway. For example, Ji and Sheng [10] took the design program FAARFIELD [11] as the analysis tool and predicted the remaining life of pavement using data by FAARFIELD with the back-calculated airport concrete pavement modulus as the prediction index. Taking the cumulative damage as the status indicator, Zhao et al. proposed the estimation method for the remaining life of flexible airport pavement and carried out case analysis [12].

Lytton applied the survival curve in highway engineering [13]. According to Lytton, the survival curve is mostly used for design of pavement maintenance and reconstruction scheme in the road network. In the performance prediction for a single section, the distribution function (i.e., survival function) is used to conduct life analysis and prediction based on preset pavement performance. Mishalani and Madanat [14]; Yang et al. [15]; and Kobayashi et al. [16] conducted a survival curve analysis according to the data of pavement performance failure, cracks in reinforced concrete bridge deck, and full cycle life cost of pavement and pointed out that the survival curve prediction analysis may be feasible for pavement engineering.

Based on the above analysis, as the remaining life prediction of airport pavement is quite complicated, scholars at home and abroad used different methods to predict the changes of pavement performance, or established suitable statistical prediction models based on the survey results of pavement performance. However, most of the methods failed to take the actual maintenance of pavement into consideration and the model only had the theoretical significance rather than could be applicable to the actual service pavement. Also, they failed to consider the reliability of service pavement and the impact of damage accumulation. In fact, there are many factors that affect the service life of airport runways, such as airport flight traffic loading, runway structural characteristics, and the level of field maintenance technology, all of which affect the remaining service life of runways. Therefore, this paper proposes a prediction method that can be used in practical engineering projects to address the effects of airport flight traffic load, runway structural characteristics, and maintenance technology level on the remaining service life.

\section{MEPDG Correction for the Remaining Life Prediction of Airport Runway}

3.1. Operation Process of MEPDG. Mechanistic-Empirical Pavement Design Guide (MEPDG) aims to provide a design and analysis method for newly built and repaired pavements based on the mechanistic-empirical principle [17].

The design method in MEPDG includes three phases. The first phase is to develop input values. The design requirements objectives are identified, basic analysis is conducted, and the characteristics data are taken as input, including the data for pavement material, the characteristics data of traffic, and the hourly climate data of weather station (temperature, precipitation, solar radiation, cloud cover, and wind speed). In the second phase, structural and performance analysis is conducted. An initial test design value is chosen and analyzed based on the relationship model between pavement response and damage (generally an expression over time). The output of the analysis is the cumulative damage and flatness over time. Based on the iteration, the predicted performance with the design indicators of multiple predicted damages has been compared until all the design indicators meet the specified reliability requirements, and the required pavement can be obtained. The third phase is to evaluate the structurally feasible alternatives, such as engineering analysis and life cycle cost analysis.

3.2. Flowchart of MEPDG Correction. Given the reliability of runway, the pass-to-coverage ratio $(\mathrm{P} / \mathrm{C})$ of aircraft model, and the cumulative damage of airport runway, MEPDG correction was needed for predicting the remaining life of airport runway. The flowchart of MEPDG correction is shown in Figure 1. 


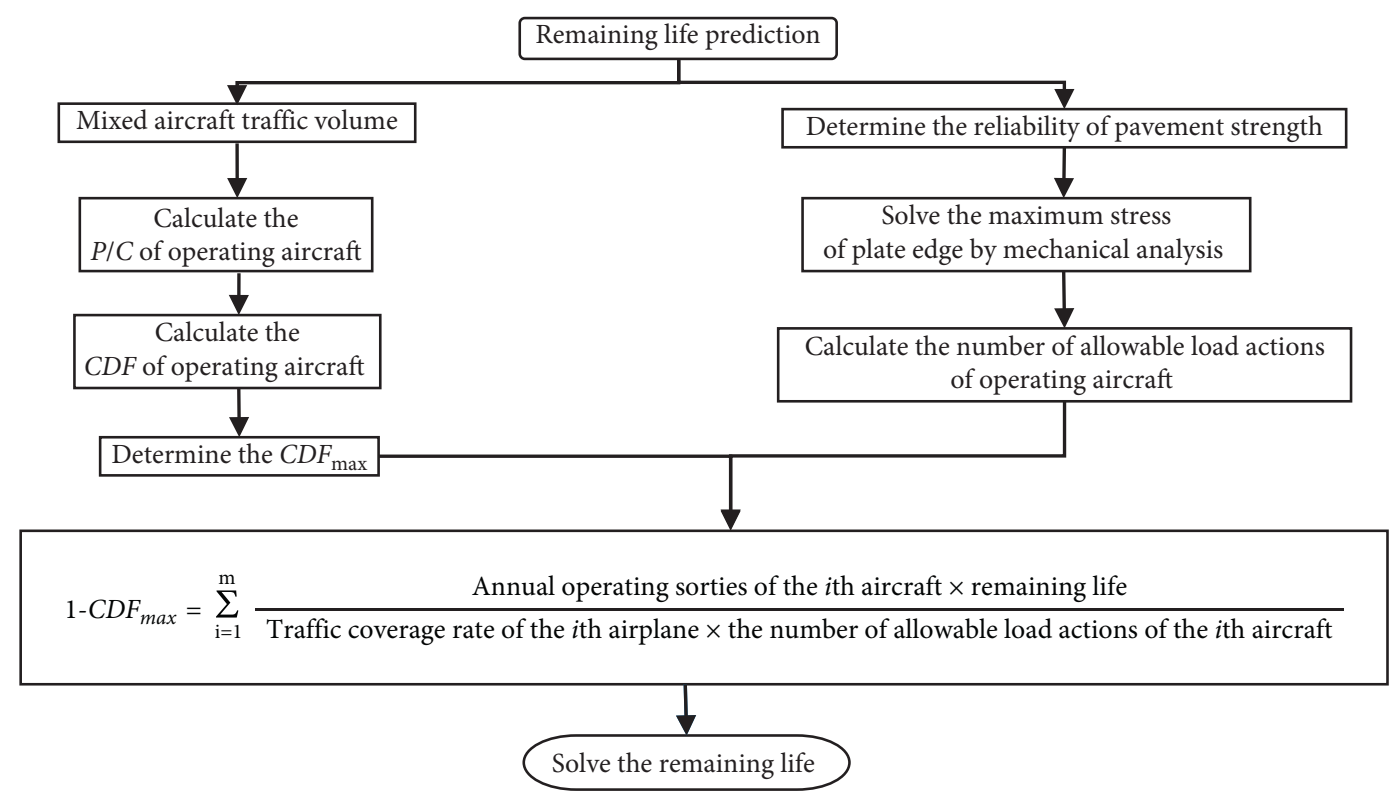

Note: $\mathrm{P} / \mathrm{C}$ in the figure was the pass-to-coverage ratio, and $\mathrm{CDF}$ was the cumulative damage factor.

FIGURE 1: Flowchart of MEPDG correction for the remaining life prediction of airport runway.

\subsection{Analysis of the Strength Reliability of the Cement Concrete} of Airport Runway Pavement. According to the Specification for Design of Highway Cement Concrete Pavement, and based on the structural characteristics of airport runway pavement, its strength reliability was explained as follows: based on the specified time and conditions, the actual probability that pavement played a specific function was obtained, as shown in the following formula [18]:

$$
P_{r}=P\left(\sigma_{\mathrm{pr}}+\sigma_{\mathrm{tr}} \leq f_{\mathrm{rm}}\right),
$$

where $P_{r}$ was the reliability achieved by the pavement; $\sigma_{p r}$ meant the fatigue stress of the pavement plate under the action of aircraft load (unit: $\mathrm{MPa}$ ); $\sigma_{t r}$ meant the flexural stress of pavement plate caused by temperature; and $f_{r m}$ referred to the standard value of flexural-tensile strength of cement concrete (unit: $\mathrm{MPa}$ ).

The corresponding function was obtained based on the limit state equation corresponding to the flexural-tensile stress, which was shown in the following formula:

$$
Z=f_{r m}-\left(\sigma_{p r}+\sigma_{t r}\right) \text {. }
$$

In this paper, the strength reliability of cement concrete of airport runway pavement needed to follow Formula (2). As the temperature and fatigue stress of cement concrete were closely related to the fatigue stress of aircraft load, the interference theory had nothing to do with and cannot help solve the strength reliability. In this paper, the control failure mode was assumed to remain constant and then a reliability analysis was conducted. According to the Specification for Design of Highway Cement Concrete Pavement and based on the different airport cement concrete pavement design and the literature proposed by Cai [19], $\lg (N)$ was obtained, as shown in the following formula by NCHRP126 fatigue equation:

$$
\begin{aligned}
\lg (N) & =\left\{\begin{array}{ll}
-1.7136 e+4.284 & e>1.25 \\
2.812 e^{-1.2214} & e \leq 1.25
\end{array},\right. \\
e & =\frac{f_{\mathrm{rm}}}{f_{\mathrm{cm}}},
\end{aligned}
$$

where $N$ was the number of coverages at $50 \%$ pavement plate cracking, namely, the fatigue life of pavement plate; $e$ referred to the stress ratio; $f_{\text {rm }}$ was the flexural-tensile fatigue strength of concrete; and $f_{\mathrm{cm}}$ meant the concrete design strength of pavement.

To make the calculation procedure simple and easy to use, the fatigue equation for temperature stress was not considered in the analysis of fatigue life.

According to the design documents and the design specifications, the flexural-tensile fatigue strength of the concrete of pavement plate usually shall be less than $1.25 f_{\mathrm{cm}}$ under aircraft load and temperature. The formula of $f_{\mathrm{rm}}$ was obtained by Formula (4), shown as follows:

$$
f_{\mathrm{rm}}=f_{\mathrm{cm}} \cdot\left(\frac{2.812}{\lg (N)}\right)^{0.8187} \text {. }
$$

By substituting Formula (5) into Formula (2), the performance function $Z$ was transformed into the following formula:

$$
Z=f_{c m} \cdot\left(\frac{2.812}{\lg (N)}\right)^{0.8187}-\sigma_{\mathrm{pr}}
$$

3.4. Calculation Principle behind the Cumulative Damage of Airport Runway. According to studies, aircraft wheel track is almost distributed in a normal manner when the aircraft 
takes off and lands. A pass of the aircraft wheel through the maximum stress point on the pavement was called a coverage. The ratio of the number of passes required to apply a full load on the pavement of unit area was expressed as the P/ C.

The statistical analysis was conducted on the distribution data of measured aircraft track, and the number of coverages was calculated based on the $\mathrm{P} / \mathrm{C}$ of aircraft on the pavement. Figure 2 (schematic diagram of the calculation of $\mathrm{P} / \mathrm{C}$ ) shows the area between $f(x)$ and $x$ axis; that is, the number of coverages during the actual operating of aircraft was equal to $l$, and the area of $W_{t}$ was $C_{x} W_{t}$. Thus, the calculation formula of the P/C of single-wheel aircraft was as follows [20]: where $P / C$ was the pass-to-coverage ratio; $C_{x}$ referred to the track probability density of operating aircraft at $x$ coordinate; and $W_{t}$ meant the effective tire contact width of aircraft, which was selected based on the design parameters of aircraft.

$$
\frac{P}{C}=\frac{1}{C_{x} W_{t}}
$$

In the airport pavement design, Miners law is widely used to show the linear cumulative fatigue damage, which can be expressed by the cumulative damage factor (CDF). As the fatigue life of pavement was expressed as the number of allowable load action repetitions, the CDF stood for the fatigue life for pavement that has been used [21]. It was equal to the ratio of the current number of actual cumulative actions on the pavement plate and the number of allowable load action repetitions of the $i$ th aircraft (the number of load action repetitions till pavement damage).

\section{Analysis on Engineering Application Case}

This paper selected the civil Airport A's runway in Henan for the case study. This airport was the Chinese trunk transport airport and a national first-class aviation port. In 2016, the passenger throughput of the airport ranked the 15th among civil airports in China. The airport was opened to traffic in 1997, and its south flight area has been used for 22 years in 2017. The south runway of the airport was $3,400 \mathrm{~m}$ long and $45 \mathrm{~m}$ wide, to grasp the comprehensive situation of the pavement in the flight area and learn about the basic information about the recent management and renovation plan of the area; the airport management department conducted comprehensive testing on the pavement of runway, taxiway, and contact surfaces in the south flight area of the airport in 2007, 2013, and 2017, respectively. The department conducted comprehensive analyses of the field test data to form a high-value database. According to the remaining life prediction process of airport runway (shown in Figure 1), the prediction for RSL of Airport A was established to verify the feasibility and implementation effect of MEPDG correction method.

4.1. Calculation on the Number of Allowable Load Actions Based on the Strength Reliability of Airport Pavement Cement Concrete. Based on the actual demands and according to the

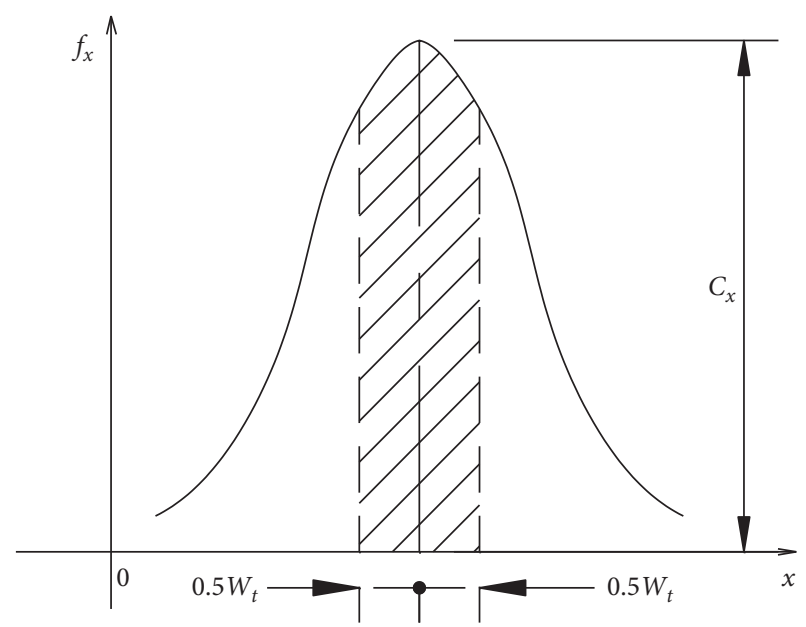

Figure 2: Schematic diagram of the calculation of P/C.

statistics of Airport A in 2017, the statistical table of the annual takeoff and landing sorties of operating aircraft at Airport A is shown in Table 1. According to Table 1, when it comes to the determination of aircraft load simulation, Boeing B737-800, Airbus A320, and Boeing B737-700 were taken into consideration in 2017.

According to the reliability calculation method under Section 3.3, the distribution type and distribution parameters of each input variable need to be defined in the reliability analysis model. Based on the literature proposed by Zhang [22] and Gao [23], and given the actual conditions of airport runway, the actual thickness of pavement plate, the response modulus of base course, the flexural-tensile design strength, and flexural-tensile modulus of surface course concrete were determined as the random variables of airport runway in this paper. The following showed the determination of the statistical properties of the random variables.

\subsubsection{Determination on the Actual Thickness of Cement} Concrete Pavement Plate. The radar detection of pavement was adopted to measure the thickness of surface layer of south runway pavement. The radar detection results of typical section are shown in Figure 3. The measured thickness of surface course of south runway pavement is shown in Table 2.

Based on Table 2, the measured thickness of surface layer of both ends of south runway pavement exceeded $37.5 \mathrm{~cm}$, fully meeting the requirement for design thickness. Based on this table, the mean thickness of surface layer of south runway pavement was determined to be $38 \mathrm{~cm}$, and the coefficient of variation was 0.03 in this paper.

4.1.2. Determination on the Modulus of Base Reaction. This paper adopted an HWD for the detection around the center of the plate. Based on the obtained HWD data and the actual pavement structure, the modulus of subgrade reaction was calculated. The back-calculated results are shown in Table 3. 
TABLE 1: Statistical table of the annual takeoff and landing sorties of operating aircraft of Airport A.

\begin{tabular}{lccc}
\hline Aircraft & Annual takeoff and landing sortie & Annual takeoff and landing ratio (\%) & Notes \\
\hline B737-800 & 38121 & 51.40 & Main model \\
A320 & 17425 & 23.50 & Main model \\
B737-700 & 4223 & 5.70 & \\
A319 & 3493 & 4.70 & \\
B737-300 & 2135 & 2.90 & \\
A321 & 2004 & 2.70 & Secondary models, with ratio less than 5\% \\
ERJ-190 & 1679 & 2.30 & \\
B747-400 & 1211 & 1.60 & \\
MA60 & 870 & 1.20 & \\
Others & 3064 & 4.10 & \\
\hline
\end{tabular}

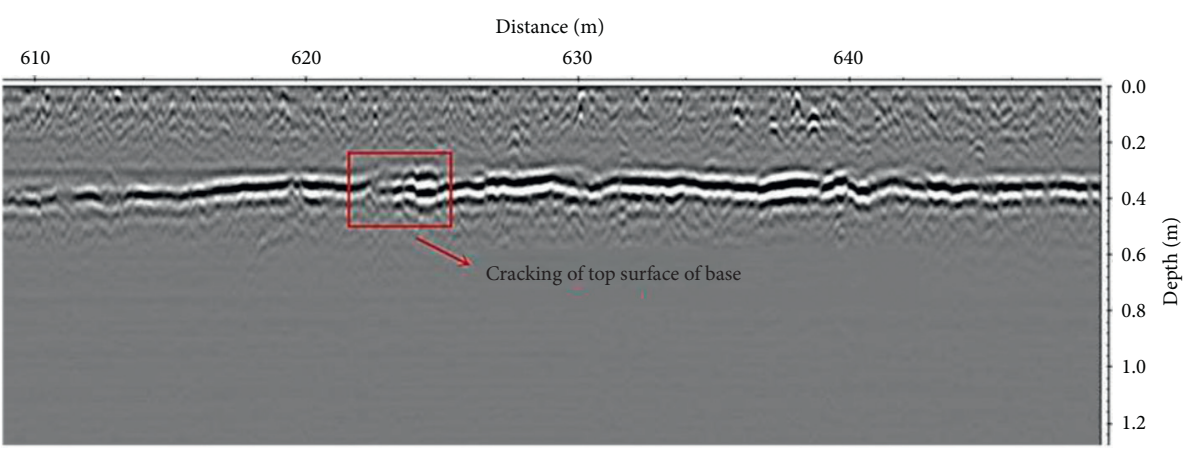

FIGURe 3: Radar detection results of typical section.

TABLE 2: Comparison between the measured thickness of runway pavement surface layer and the design thickness.

\begin{tabular}{lcccccc}
\hline Section & Position $(\mathrm{m})$ & $\begin{array}{c}\text { Number of sample } \\
(\mathrm{pcs})\end{array}$ & $\begin{array}{c}\text { Full-thickness mean } \\
(\mathrm{cm})\end{array}$ & $\begin{array}{c}\text { Standard deviation } \\
(\mathrm{cm})\end{array}$ & $\begin{array}{c}\text { Representative value } \\
(\mathrm{cm})\end{array}$ & $\begin{array}{c}\text { Design value } \\
(\mathrm{cm})\end{array}$ \\
\hline \multirow{2}{*}{ South } & $0-500 \mathrm{~m}$ & 500 & 38.18 & 1.32 & 38.08 & 38 \\
runway & $500-2900 \mathrm{~m}$ & 2400 & 34.01 & 1.79 & 33.95 & 34 \\
& $2900-3400 \mathrm{~m}$ & 500 & 38.06 & 1.7 & 37.93 & 38 \\
\hline
\end{tabular}

TABle 3: Calculation table of the modulus of the subgrade reaction and the base reaction of south runway pavement.

\begin{tabular}{|c|c|c|c|c|}
\hline \multicolumn{2}{|c|}{ Zone (m) } & $\begin{array}{l}\text { Modulus of subgrade reaction (MN/ } \\
\left.\qquad \mathrm{m}^{3}\right)\end{array}$ & $\begin{array}{l}\text { Equivalent thickness of base course } \\
\qquad(\mathrm{cm})\end{array}$ & $\begin{array}{l}\text { Modulus of base reaction (MN/ } \\
\left.\mathrm{m}^{3}\right)\end{array}$ \\
\hline \multirow{3}{*}{ Runway } & $0-500$ & 58 & 48 & 104 \\
\hline & $500-2900$ & 52 & 48 & 100 \\
\hline & $2900-3400$ & 47 & 48 & 95 \\
\hline
\end{tabular}

The pavement foundation comes from the compacted pavement bed soil, and the pavement foundation modulus is often affected by the material properties. It is worth noting that the environmental factors directly affect the performance of the pavement foundation, and the significant differences in soil quality also directly affect varied characteristics of pavement foundation. Considering the above factors and the variation coefficient in the literature proposed by $\mathrm{Li}$ [24], the variation coefficient of the modulus of base reaction was set as 0.3 .

4.1.3. Determination on the Flexural Strength and the Elastic Modulus of Airport Runway Cement Concrete. The sampling scheme of pavement core was as follows: in the south runway, a total of 18 core samples were drilled alternately every $180 \mathrm{~m}$ along both sides of the centerline. The drilled cement concrete core samples shall be subject to the splitting tensile strength test according to the Technical Specification for Construction of Cement Concrete Surface of Civil Airport. The test results of the drilled cement concrete core samples are shown in Table 4 . The section structures of typical cement concrete core samples after the test are shown in Figure 4.

According to Table 4, the mean of the flexural strength of cement concrete of runway pavement surface course was $5.78 \mathrm{MPa}$, and the coefficient of variation was 0.15 ; the mean of the flexural elastic modulus was $38,537.77 \mathrm{MPa}$, and the coefficient of variation was 0.09 . Given the fact that the airport pavement cement concrete has been used for nearly 
TABLE 4: Tensile strength test results of the cement concrete core samples of runway pavement.

\begin{tabular}{|c|c|c|c|c|c|}
\hline $\begin{array}{l}\text { Core sample } \\
\text { no. }\end{array}$ & $\begin{array}{l}\text { Test piece diameter }(\mathrm{mm}) / \\
\text { height }(\mathrm{mm})\end{array}$ & $\begin{array}{l}\text { Failure load } \\
(\mathrm{kN})\end{array}$ & $\begin{array}{l}\text { Splitting strength } \\
(\mathrm{MPa})\end{array}$ & $\begin{array}{l}\text { Flexural strength } \\
(\mathrm{MPa})\end{array}$ & $\begin{array}{l}\text { Flexural elastic modulus } \\
(\mathrm{MPa})\end{array}$ \\
\hline $1 \#$ & $147.5 / 203$ & 139.807 & 2.97 & 4.82 & 34342.65 \\
\hline $2 \#$ & $147.5 / 198$ & 161.641 & 3.52 & 5.59 & 37922.91 \\
\hline $3 \#$ & $147.5 / 199$ & 197.105 & 4.27 & 6.62 & 42192.64 \\
\hline $4 \#$ & $147.5 / 201$ & 175.513 & 3.77 & 5.93 & 39387.19 \\
\hline $5 \#$ & $147 / 301$ & 211.352 & 3.04 & 4.92 & 34811.10 \\
\hline $6 \#$ & $147.5 / 299$ & 279.592 & 4.04 & 6.3 & 40901.97 \\
\hline 7\# & $147.5 / 302$ & 202.168 & 2.89 & 4.71 & 33763.08 \\
\hline $8 \#^{*}$ & $147 / 301$ & 285.587 & 4.11 & 6.4 & 41302.77 \\
\hline 9\# & $146.5 / 299$ & 201.403 & 2.93 & 4.76 & 34027.75 \\
\hline $10 \#$ & $147 / 300$ & 262.883 & 3.79 & 5.97 & 39539.02 \\
\hline $11 \#$ & $148 / 298$ & 303.461 & 4.38 & 6.76 & 42743.19 \\
\hline $12 \#$ & $148 / 297$ & 337.33 & 4.89 & 7.44 & 45241.95 \\
\hline $13 \#^{*}$ & $148 / 301$ & 324.969 & 4.64 & 7.12 & 44075.51 \\
\hline $14 \#$ & $147.5 / 298$ & 307.293 & 4.45 & 6.86 & 43104.91 \\
\hline $15 \#$ & $148 / 298$ & 283.163 & 4.09 & 6.37 & 41184.52 \\
\hline $16 \#$ & $147.5 / 300$ & 236.735 & 3.41 & 5.43 & 37193.95 \\
\hline $17 \#^{*}$ & $147.5 / 298$ & 194.210 & 2.81 & 4.6 & 33220.36 \\
\hline $18 \#$ & $148 / 302$ & 224.617 & 3.2 & 5.14 & 35868.57 \\
\hline \multicolumn{4}{|c|}{ Mean $(\mathrm{MPa})$} & 5.78 & 38537.77 \\
\hline \multicolumn{4}{|c|}{ Standard deviation (MPa) } & 0.84 & 3605.52 \\
\hline \multicolumn{4}{|c|}{ Representative value at $95 \%$ guarantee rate $(\mathrm{MPa})$} & 5.39 & 36897.26 \\
\hline
\end{tabular}

Note. The 8 \#, 13 \#, and 17 \# core samples were not completely split, so their data were discarded in this calculation.

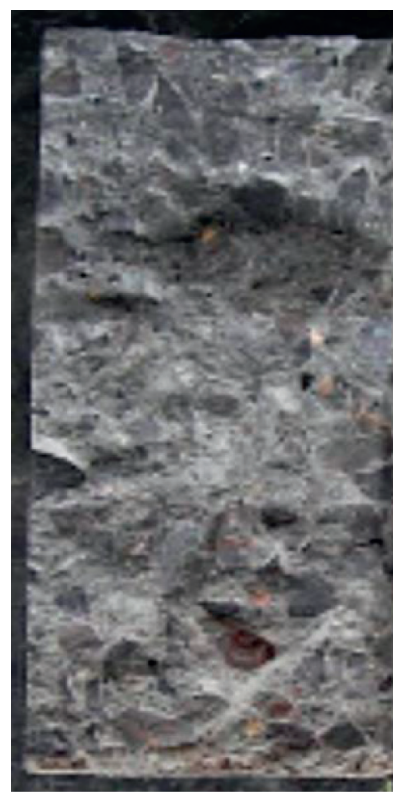

(a)

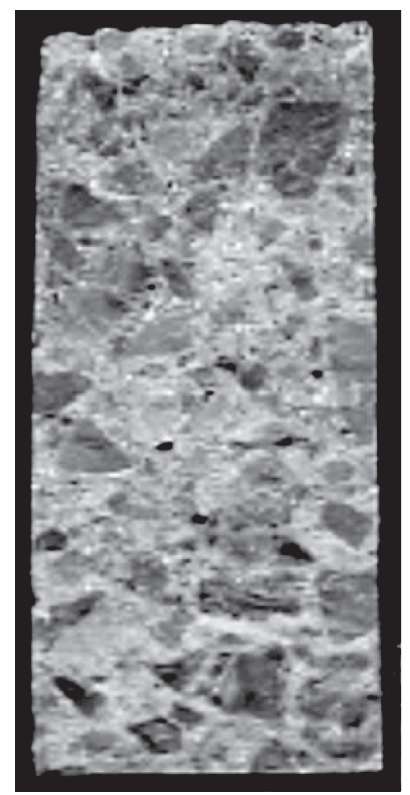

(b)

FiguRE 4: Section structures of typical cement concrete core samples after the splitting tensile strength test. (a) Core sample \# 7 . (b) Core sample \# 12.

20 years and for the sake of design safety, the mean of the flexural strength of cement concrete of runway pavement surface course was set as $4.50 \mathrm{MPa}$, and the coefficient of variation took 0.15 .

4.1.4. Number of Allowable Load Actions of the Cement Concrete Runway of the Operating Airport. According to the calculation method of reliability under Section 3.3 mentioned above, the distribution parameters of input variables were defined. The thickness of surface course, the strength and modulus of surface course, and the modulus of base reaction were regarded as random variables. Except for the distribution of the modulus of base reaction which was in logarithmic normal distribution, the other random variables tended to be in normal distribution. 
The semirigid base of that airport runway pavement is likely to crack and lead to the damage of the base. At the same time, the coefficient of variation will increase. These problems generally occur in the early stage of the runway. Therefore, the random variables of runway were set according to the actual detection values described above. Based on the literature proposed by Guo [25] and Gao [26], the appropriate interval for coefficient of variation was set; the scientific and effective quality control was generally made on the surface course during construction; the base showed significant deformation. The mean and coefficient of variation of the random variables are shown in Table 5.

Take the load of twin-wheel B737-800 as an example. The load was distributed in the middle of the cross-seam edge of pavement plate because of the spacing of wheels. Based on the target reliability of II, III, and IV airports in the literature proposed by Li [27], the target reliability was set to $95 \%$. By inputting the target reliability into the numerical analysis program, the allowable action times of B737-800 aircraft acting on the pavement were calculated. The specific results are as follows.

In general, the response surface method for reliability analysis does not experience many cycles and can be analyzed in low probability. The fitting coefficient can represent the approximation between the actual response values, and can inform the users to update the definition parameters with the poor effect of the fitting of approximate function, so it is ideal for parallel processing. Thus, when calculating reliability, this paper used the Box-Behnken matrix sampling of response surface method for analyzing probability [28]. The precision test of response surface followed the formula as [29]

$$
R^{2}=\frac{\sum_{i=1}^{n}\left(\hat{y}_{i}-\bar{y}\right)^{2}}{\sum_{i=1}^{n}\left(y_{i}-\bar{y}\right)^{2}},
$$

where $\hat{y}_{i}$ was the calculation value of response surface model; $y_{i}$ referred to the true value (calculation result of finite element analysis); and $\bar{y}$ was the average value corresponding to true value. $R^{2}$ ranged from $0-1$. If $R^{2}$ was large, the regression model will be more fit with the actual case.

Based on the square response surface regression results, the comparison between the response surface estimation value and the finite element true value was made, as shown in Figure 5. As can be seen from Figure 5, except for the individual data points, the other data points were distributed near the $45^{\circ}$ line, which indicated that there was good fitting between the response surface estimation value and the finite element true value.

For the response surface functions that have been fitted, the Monte-Carlo method was used for 10,000 times of sampling and a series of performance function corresponding to the sampling value distribution diagram was obtained (see Figures 6 and 7 for details). Due to the limited space, the following only listed the figure of performance functions during the B738 load action.

As can be seen from Figures 6 and 7, sampling based on the response surface function will achieve excellent convergence. Thus, the number of samples was set to $10^{4}$ to meet the preproposed reliability standard. At this point, the failure probability reached $P_{f}=5.412 \times 10^{-2}$, and $z$ at $95 \%$ target reliability was $0.476 \mathrm{Mpa}$. By substituting it into Formula (5), the number $(\mathrm{N})$ of allowable load actions of B738 meeting 95\% target reliability was 133,195 . Similarly, 4,175,184 times of allowable load actions of A320 and 477,806 times of allowable load actions of B737-700 met 95\% target reliability, respectively.

4.2. Calculation of Airport Pavement CDF and the RSL Prediction Based on P/C. As mentioned above, the B737-800, A320, and B737-700 were the major aircraft of Airport A since the calculation of CDF needed the number of coverages of aircraft loads, which must be converted through the takeoff and landing sorties of different aircraft by means of $\mathrm{P} / \mathrm{C}$. So, separate calculation was required for the major aircraft of Airport A. Because the runway cumulative damage factor CDF is calculated based on the number of aircraft load coverage, and the number of aircraft load coverage needs to be converted by the number of takeoff and landing sorties of different aircraft types through the $\mathrm{P} / \mathrm{C}$ of traffic coverage, it needs to be calculated for the main aircraft types of Airport A, respectively.

Based on the theoretical analysis under Section 3.4 aforementioned, given the B738 parameters, the main landing gear spacing of single-wheel B738 was set to $T_{W}$, and then the wheel track status of its left and right wheels was determined. If $T_{W}$ was less than or equal to the passage width of aircraft pavement, the tracks of the left and right wheels did not coincide. In this process, the main landing gear spacing was $5.72 \mathrm{~m}$, the wheel spacing was set to $0.86 \mathrm{~m}$, and the standard deviation in the $x$ direction took $0.775 \mathrm{~m}$ according to the data from Federal Aviation Administration (2012). The distribution function for the wheel track curve of the main landing gear spacing of B738 was as follows:

$$
F(x)=\frac{1}{0.775 \sqrt{2 \pi}} e^{-1 / 2(x+3.29 / 0.775)^{2}}+\frac{1}{0.775 \sqrt{2 \pi}} e^{-1 / 2(x+2.43 / 0.775)^{2}} .
$$

Through calculation, when $x=2.86 \mathrm{~m}$, the maximum function value was 0.8827 , the wheelmark width reached $0.296 \mathrm{~m}$, and the $\mathrm{P} / \mathrm{C}$ was about 3.83 based on Formula (7).

According to the above methods, the P/C of A320 and B737-700 was calculated and the results are summarized in Table 6. According to the number of allowable load actions for various aircraft calculated under Section 4.1, the CDF of the major aircraft can be calculated based on the actual traffic volume of Airport A in 2017, as shown in Table 6.

In this paper, the annual average growth rate of different aircraft models in the airport pavement evaluation stage was 0.20 based on trend extension method. In this way, the number of annual aircraft operations in future can be estimated and the cumulative pavement damage can be calculated (see Table 7 for details). Given the predicted average annual cumulative damage of 0.2568 and the remaining fatigue strength of 0.2958 , the remaining life of pavement was predicted to be 0.2958 / $0.2568=1.15$ years. The Airport A has been shut down for maintenance and renovation in 2019, which was consistent with the remaining life predicted in this paper. 
TABLE 5: Mean and coefficient of variation of the random variables.

\begin{tabular}{lcccc}
\hline Random variable & Surface thickness & Flexural strength & Modulus of surface course & Modulus of base reaction \\
\hline Mean & $0.38 \mathrm{~m}$ & $4.5 \mathrm{MPa}$ & $38.54 \mathrm{GPa}$ & $100 \mathrm{MPa}$ \\
Coefficient of variation & 0.03 & 0.15 & 0.09 & 0.3
\end{tabular}

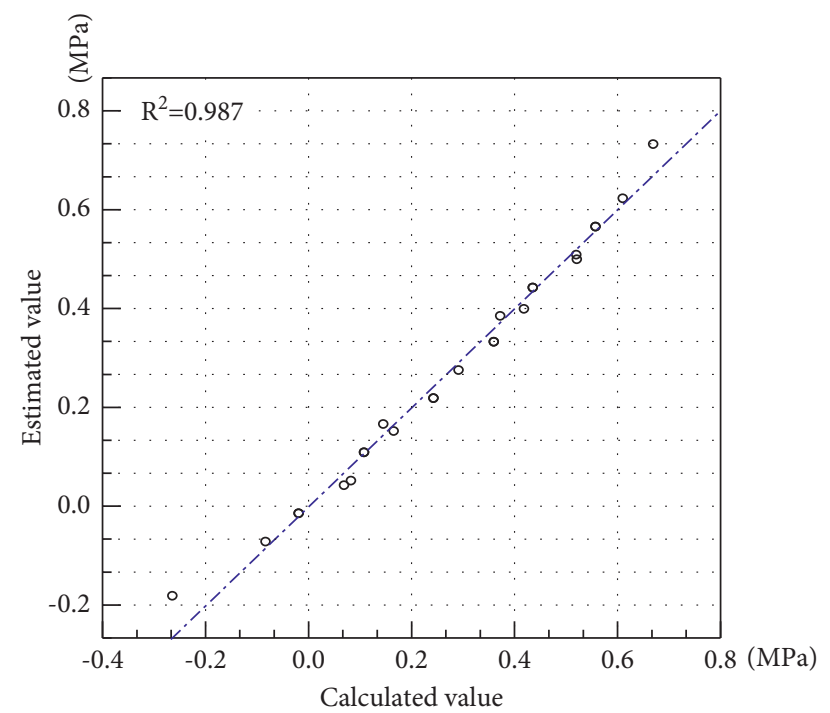

FIGURE 5: Comparison between the response surface estimation value and the finite element true value (B738).

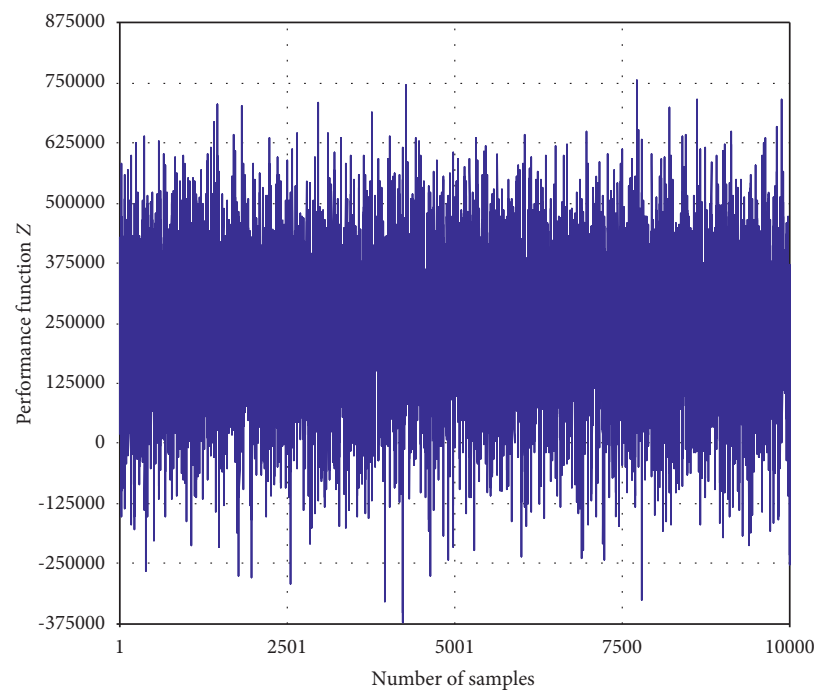

FIgURE 6: Sampling value distribution diagram of performance function Z (B738). 


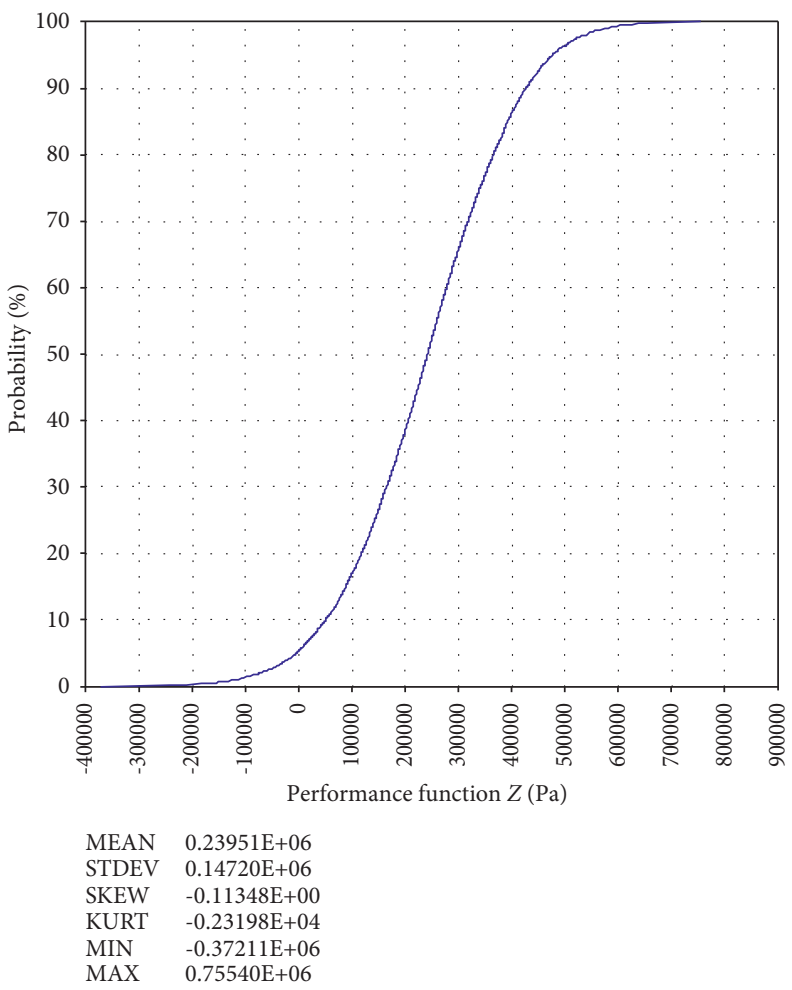

FIgURE 7: Cumulative probability distribution diagram of performance function $\mathrm{Z}$ at $95 \%$ reliability level (B738).

TABLE 6: Summary on the P/C and CDF of different aircraft.

\begin{tabular}{|c|c|c|c|}
\hline Airplane & B737-800 & A320 & B737-700 \\
\hline Tire contact width $W_{\mathrm{t}}(\mathrm{m})$ & 0.296 & 0.235 & 0.287 \\
\hline Value of $x$ & 2.86 & 3.8 & 2.86 \\
\hline Maximum probability function value $F(x)$ & 0.8827 & 0.9071 & 0.8827 \\
\hline Pass-to-coverage ratio $\mathrm{P} / \mathrm{C}$ & 3.83 & 4.69 & 3.95 \\
\hline Number of allowable load actions & 133195 & 4175184 & 477806 \\
\hline Number of actual cumulative coverages & 91584 & 34186 & 9837 \\
\hline $\mathrm{CDF}$ & 0.6876 & 0.0082 & 0.0085 \\
\hline Sum of cumulative fatigue consumption of each model $\sum \mathrm{CDF}$ & & 0.7042 & \\
\hline Remaining fatigue strength of pavement & & 0.2958 & \\
\hline
\end{tabular}

TABle 7: Prediction for the annual average cumulative damage of different aircraft models.

\begin{tabular}{|c|c|c|c|}
\hline Airplane & B737-800 & A 320 & B737-700 \\
\hline Number of annual average operations in future & 125737 & 57474 & 13929 \\
\hline Pass-to-coverage ratio $\mathrm{P} / \mathrm{C}$ & 3.83 & 4.69 & 3.95 \\
\hline Number of annual repeated actions & 32830 & 12255 & 3526 \\
\hline Maximum number of allowable actions & 286719 & 96762 & 1162864 \\
\hline Fatigue consumption & 0.2465 & 0.0029 & 0.0074 \\
\hline Sum of the fatigue consumption of each model & & 0.2568 & \\
\hline
\end{tabular}

Note. The data in the table were those predicted of an airport in 2017. 


\section{Conclusions}

In this paper, the remaining life prediction method of airport runway was analyzed. The operation process of MEPDG was analyzed and summarized, and the MEPDG correction method was applied to the remaining life prediction of the airport runway. Since the airport runway was different from the expressway, the reliability calculation method of finite element numerical analysis was used to deal with the design stress of pavement plate edge that met $95 \%$ target reliability. The remaining life of airport runway was analyzed based on the actual data from the MEPDG correction method. The main conclusions were as follows:

(1) According to the theory of structural reliability, the performance function of airport pavement was obtained based on the limit state equation represented by flexural stress; the calculation formula of the number of allowable load actions can be obtained based on reliability by NCHRP126 fatigue equation without considering the temperature stress when the flexural fatigue strength of pavement plate cement concrete was less than $1.25 f_{\mathrm{cm}}$.

(2) This paper selected a runway of the civil airport in Henan as the application case and adopted the MEPDG correction method. The flexural stress of the actual operating airport runway pavement at 95\% reliability level was analyzed based on the mechanical numerical model of airport runway, and the number of allowable load actions of three aircraft models was obtained; given the impact of $\mathrm{P} / \mathrm{C}$, the CDF of the major aircraft models was calculated; the annual average growth rate of different aircraft models in the airport pavement evaluation stage was 0.20 obtained based on the trend extension method. In this way, the number of annual aircraft operations in future can be estimated and the cumulative pavement damage could be calculated. Given the predicted average annual cumulative damage of 0.2568 and the remaining fatigue strength of 0.2958 , the remaining life of pavement was predicted to be 1.15 years. Airport A has been shut down for maintenance and renovation in 2019, which was consistent with the remaining life predicted in this paper.

\section{Data Availability}

The figure and table data used to support the findings of this study are included in the paper. In addition, the data and the models of analysis are available from the corresponding author upon request.

\section{Conflicts of Interest}

The authors declare that there are no conflicts of interest regarding the publication of this paper.

\section{Acknowledgments}

This research was funded by the Key Research Program in Universities of Henan Province (No. 21B580008) and the Science and Technology Project of Henan Province (No. 182102310747), for which the authors are grateful.

\section{References}

[1] Z. S. Quan, Q. Wang, and Z. X. Wu, Intelligent Technology and Industrial Application, pp. 268-270, Shanghai Science and Technology Press, Shanghai, China, 2019.

[2] H. Huang, M. Huang, W. Zhang, S. Pospisil, and T. Wu, "Experimental investigation on rehabilitation of corroded RC columns with BSP and HPFL under combined loadings," Journal of Structural Engineering, vol. 146, no. 8, Article ID 04020157, 2020.

[3] M. Y. D. M. Shahin, "Development of a pavement maintenance management system," Airfield Pavement Distress Identification Manual. concrete pavements, vol. II, 1976.

[4] T. Freeman and G. B. Dresser, Update: Implementation of the Micropaver Pavement Management System on texas Division of Aviation Airfields, Texas A\&M University, College Station, Texas, 1999.

[5] L. J. Sun and X. P. Liu, "General deterioration equation for pavement performance," Journal of Tongji University, vol. 5, pp. 512-518, 1995.

[6] S. A. Kwon, H. S. Yang, and Y. C. Suh, "Development of fatigue model for airfield concrete pavement," International Journal of Highway Engineering, vol. 6, no. 3, pp. 27-35, 2004.

[7] J. M. Ling, Y. F. Zheng, and J. Yuan, "Prediction model of remaining life for asphalt concrete pavement of runway," Journal of Tongji University, vol. 4, pp. 56-59, 2004.

[8] M. A. Mooney, V. Khanna, J. Yuan, T. Parsons, and G. A. Miller, "Web-Based pavement infrastructure management system," Journal of Infrastructure Systems, vol. 11, no. 4, pp. 241-249, 2005.

[9] H. P. Bell, I. L. Howard, R. B. Freeman, and E. R. Brown, "Evaluation of remaining fatigue life model for hot-mix asphalt airfield pavements," International Journal of Pavement Engineering, vol. 13, no. 4, pp. 281-296, 2012.

[10] R. Ji and B. Sheng, "Reliability considerations of airport concrete pavement design using variation of back calculated modulus," in Proceedings of the International Conference on Transportation and Development 2018: Airfield and Highway Pavements, pp. 45-55, Pittsburgh, Pennsylvania, USA, July 2018.

[11] D. R. Brill and I. Kawa, "Advances in FAA pavement thickness design software: FAARFIELD 1.41," in Proceedings of the International Conference on Highway Pavements and Airfield Technology 2017, pp. 92-102, Philadelphia, Pennsylvania, USA, August 2017.

[12] H. Zhao, L. Ma, and J. Zhang, "Estimating the remaining life of airfield flexible pavements considering environmental factors," HKIE Transactions, vol. 25, no. 3, pp. 208-216, 2018.

[13] R. L. Lytton, "Concepts of pavement performance prediction and modeling," in Proceedings of the Second North American Conference on Managing Pavements, Toronto, Canada, November 1987.

[14] R. G. Mishalani and S. M. Madanat, "Computation of infrastructure transition probabilities using stochastic duration models," Journal of Infrastructure Systems, vol. 8, no. 4, pp. 139-148, 2002. 
[15] Y. N. Yang, H. J. Pam, and M. M. Kumaraswamy, "Framework development of performance prediction models for concrete bridges," Journal of Transportation Engineering, vol. 135, no. 8, pp. 545-554, 2009.

[16] K. Kobayashi, K. Kaito, and N. Lethanh, "Deterioration forecasting model with multistage Weibull Hazard functions," Journal of Infrastructure Systems, vol. 16, no. 4, pp. 282-291, 2010.

[17] C. L. Ji and H. L. Zhang, "Introduction to asphalt pavement mechanics - empirical design method (MEPDG)," Journal of Highway and Transportation Research and Development, vol. 12, no. 10, pp. 119-121, 2016.

[18] China Communications Highway Planning and Design Institute Co., Ltd, JTG D40-2011 Specifications for Design of Highway Cement concrete Pavement, China Communications Press Co., Ltd., Beijing, China, 2011.

[19] L. C. Cai, H. F. Wang, and L. L. Zhang, "Prediction model of remaining life for airport pavement based on cumulative damage," Journal of Traffic and Transportation Engineering, vol. 14, no. 4, pp. 1-6, 2014.

[20] K. Izydor, "Pass-to-Coverage computation for arbitrary gear configuration in the FAARFIELD program. SRA, International. Federal Aviation Administration," Report No. DOT/ FAA/TC-TN12/47, 2012.

[21] Federal Aviation Administration, "Airport pavement design and evaluation," Advisory Circular (AC) 150/5320-6F, November 10, 2016.

[22] L. L. Zhang, Geotechnical Engineering Reliability Theory, Tongji University Press, China, 2011.

[23] G. Mingzhong, H. Haichun, X. Shouning et al., "Discing behavior and mechanism of cores extracted from Songke-2 well at depths below 4,500 m," International Journal of Rock Mechanics and Mining Sciences, vol. 149, Article ID 104976, 2022.

[24] L. Li and G. P. Cen, "Effect of parameter design value on reliability of airfield cement concrete pavement," Sichuan Building Science, vol. 34, no. 4, pp. 89-92, 2008.

[25] S. H. Guo, Research on the Reliability Evaluation Method of Cement concrete Pavement Structure, Harbin Institute of Technology, Harbin, 2014.

[26] M. Z. Gao, J. Xie, Y. N. Gao et al., "Mechanical behavior of coal under different mining rates: a case study from laboratory experiments to field testing," International Journal of Mining Science and Technology, vol. 31, no. 2021, pp. 825-841, 2021.

[27] L. Li, Research on Reliability Design Method of Airport Cement concrete Pavement, Air Force Engineering University, Xi'an, China, 2006.

[28] M. Saeed, Finite Element Analysis: ANSYS Theory and Applications, Electronic Industry Press, China, 4th edition, 2015.

[29] D. C. Montgomery, Design and Analysis of Experiments, Wiley, New York, NA, USA, 2003. 